establishing confidential inquiries into the circumstances in which young patients die from their disease-in a similar manner to the inquiries currently performed into maternal deaths. In this way we may identify risk factors more certainly and eventually prevent more deaths.

${ }^{1}$ British Medical fournal, 1978, 1, 873.

2 Office of Health Economics, Asthma. London, OHE, 1976.

${ }^{3}$ MacDonald, J B, Seaton, A, and Williams, D A, British Medical fournal, 1976, 1, 1493.

${ }^{4}$ Bateman, J R M, and Clarke, S W, Thorax, 1979, 34, 40.

${ }^{5}$ McFadden, E R, Kiser, R, and DeGroot, W J, New England fournal of Medicine, 1973, 288, 221.

${ }^{6}$ Speizer, F E, et al, British Medical fournal, 1968, 1, 339

Bellamy, D, and Collins, J V, Thorax, 1979, 34, 36.

${ }^{8}$ Cochrane, G M, and Clark, T J H, Thorax, 1975, 30, 300.

${ }^{9}$ Crompton, G K, and Grant, I W B, British Medical fournal, 1975, 4, 680.

${ }^{10}$ Clark, T J H, and Godfrey, S, (editors), Asthma. London, Chapman and Hall, 1977.

\section{Emergencies and the laboratory}

The much-publicised rise in the work load of laboratories has been accompanied by a parallel increase in requests for emergency tests throughout the 24 hours. In most British laboratories, out-of-hours emergency requests are dealt with satisfactorily, albeit expensively, by arrangements such as on-call rotas. Conflicts seldom arise provided the rota is adequately staffed, though on occasions clinicians request a test in the middle of the night that is not normally regarded by the laboratory worker as an emergency procedure.

Conflicts are more common when, during normal working hours, the result of a test is demanded more quickly than the normal turn-round time for that test, so that "urgent" becomes equated with "emergency." Difficulty occurs, especially in clinical chemistry, because logistic problems develop from the laboratory trying to handle "one-offs" at the same time as processing its daily work. The competing demands on both staff and equipment induce stress, and if the number of urgent requests during normal working hours is high they can hinder the routine service, thereby increasing the demand for urgent answers even further.

This chain reaction appears to have occurred in the Ontario teaching hospitals, where recently one in four requests for general clinical chemistry was classed as urgent. To overcome this problem Henderson ${ }^{1}$ introduced two additional forms: one which he called a priority test request form and another the telephone results form, which is printed on the back of the priority request form. The first of these lists the tests available as priorities, permits up to five to be ordered, indicates the time by which the result is required (15 minutes, 1 hour, 2 hours, 3 hours, or today), and to whom and at what number the results are to be telephoned. The telephone request form is used for non-priority tests, and gives only two times (three hours or today). Henderson claims that in many cases "urgent" has been misinterpreted or even misused by the clinician, and that by categorising the test request into a known time-scale the test can often be accommodated within routine batches. Since the introduction of the new forms laboratory staff have been able to organise their work more effectively, while the clinicians' real needs have still been met. Resistance to introducing the new forms had to be overcome by intensive education. The number of urgent requests fell almost to nil for the first 10 days but is now back to its previous level, though the number of tests per request has halved. Relations between clinician and laboratory are said to have improved though no objective evidence is presented.

Are there lessons here for British laboratories? Undoubtedly the number of urgent requests is higher than necessary. This is probably due to several factors, including too slow a turn-round between requesting and receiving the report, misunderstandings about how long certain tests take, covering up previous omissions, and simple convenience. Is the concept of priority for requests the answer? Making priority more difficult may, in fact, mean that only real needs are met. Telephoning too many results is not only time-consuming but may interrupt a clinician at an unsuitable time-and as a means of accurate communication the telephone leaves much to be desired. Is it really necessary to introduce special forms? The required time-scale can be indicated on existing forms, and if a request really is urgent, the clinician should make personal contact with the laboratory physician. Henderson's study might have been more convincing had it shown that the clinicians actually used the results on the time-scale they requested them and had he removed rather than reduced the current misuse of the "urgent" request, thereby reducing or at least containing laboratory costs.

${ }^{1}$ Henderson, A R, fournal of Clinical Pathology, 1979, 32, 97.

\section{Review Body reports}

The Review Body has done as it promised last year. ${ }^{1}$ The delayed ninth report ( $\mathrm{p}$ 1577), published as the $B M \mathcal{F}$ went to press, recommends an average increase of $25.7 \%$ for NHS doctors and dentists from 1 April 1979, an award that will add $£ 199$ m to the professions' pay bill. This is made up of a $12 \%$ cost-of-living increase in addition to the second instalment of the three-phase increase (corrected in the light of updated information), which the Review Body recommended last year was necessary to bring NHS doctors' incomes back into line with comparable groups. So hopes that the Review Body might bring forward phase three of the award from 1 April 1980 to this year, as requested by the BMA (p 1579), have not materialised. The profession will look askance at the reason given, namely, to contain inflation, because it conflicts with the Pilkington Commission's recommendation that NHS doctors' pay should not be used as a regulator of the national economy. ${ }^{2}$ But with long queues at medical schools and comparability pay reviews for other NHS staff still under way doctors will not be unduly surprised that the Government has failed to do for them what it did for the police and armed Forces and pay off its debts now.

This report is a special one on two counts. Firstly, consultants had submitted extensive evidence for the pricing of their new contract ${ }^{3}$ and, secondly, the juniors had not submitted any evidence, as their representatives want no part of the Review Body system and are seeking, unsuccessfully so far, direct negotiations with the DHSS on pay. ${ }^{4}$ Nevertheless, the Review Body has pronounced on hospital junior staff pay, recommending straightforward increases of around $22 \%$. While the juniors, however, are dealt with in one short paragraph, the consultants' present and new contracts occupy several pages of the 127-page report.

Because consultants would be given a choice of staying with the present contract or changing to the new one-if it was accepted by the profession-there are two sets of recom- 